\title{
Analyzing the Relationship between Ethical Marketing and Strategic Balance : An a Comparative Study in a Sample of Companies in the Industrial Sector in the Provinces of Babylon and Holly Karbala'
}

\author{
Adel Hadi Albaghdadi ${ }^{\mathrm{a}} \quad$ May Mohammed Dhafer $^{\mathrm{b}}$ \\ ${ }^{a}$ University of Babylon \\ ${ }^{b}$ Martyrs Foundation - Babil \\ uniheadoffice@uobabylon.edu.iq \\ may.m.dhafer@gmail.com
}

Submission date:- 6/12/2018 Acceptance date:- 31/12/2018 Publication date:- 20/2/2019

Keywords:Ethical Marketing, Strategic Balance,Honesty,Responsibility, Respect, Fairness, Capability, Opportunities, Internal Environment, Goals.

\begin{abstract}
Objective: The objective of our present study is to analyze the relationship between ethical marketing and strategic balance in the sample companies represented by the private and public companies operating in the industrial sector in the provinces of Babylon and Holly Karbala.

Methodology/ Design: The problem of the study was formulated through several questions regarding the relationship between the variables of the study and its nature by which the objectives of the study were identified and represented in hypothetical scheme which shaped the formulation of the hypotheses that were scaled in the advanced statistical program "partial least squares structural equation modeling (PLS-SEM)" by analyzing data provided by the research tool (questionnaire) after applying it on the research community members who have been picked randomly: sections and branches managers from different administrative levels. (57) Questionnaires were distributed to public and private sector companies, (54) have been retrieved and (4) were excluded for being invalid so the final number is (50). For the analysis of data, the researcher used a set of statistical methods in the advanced statistical program (SmartPLS V.3) for data analysis because of the scarcity of research and studies using this advanced program and the accuracy of its results that can help in reaching objective and precise conclusions, as well as the use of (SPSS v22) to evaluate the scaling tools.

Theoretical results: there is an ambiguous perception concerning the nature of relation among current study variables represented in independent variable (Ethical Marketing) and subsidiary variable (Strategic Balance).

Practical results: the most important practical results reached by the researcher can be summarized in the presence of a relation of direct, positive and moral effect between ethical marketing and strategic balance of both sectors.

The value and authenticity of the study: The value of the research lies in establishing the rules of knowledge and concepts of its variables through clarifying the relation of direct, positive and moral impact on these variables after applying them to the constituents of the study society and through a comparison that resulted in the superiority of private sector companies in their application of ethical marketing that achieves strategic balance and directing it towards the sector of a great impact on the Iraqi economy.
\end{abstract}




\section{تحليل العلاقة بين التسويق الاخلاقي و التوازن الاستراتيجي

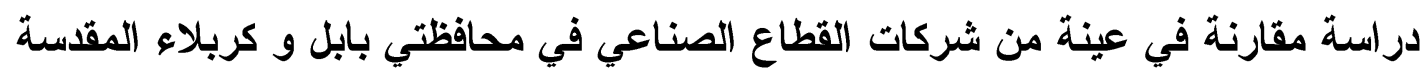

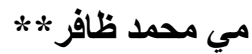 \\ عادل هادي البغدادي

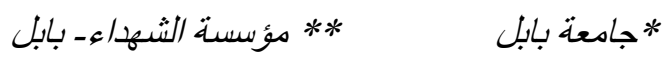 \\ may.m.dhafer@gmail.com}

الخلاصة

الغرض:إنّ الهدف الرئيس للبحث هو تحليل العلاقة بين التسويق الاخلاقي و التوازن الاستراتيجي في الثركات العامة و الخاصــة العاملـــة فـي القطاع الصناعي في محافظتي بابل و كربلاء المقدسة.

المنهجية/التصميم:صيغت مشكلة البحث من خلال عدة تساؤلات فيما يخص العلاقة بين متغير اته وطيبعتها و التي على اثرها حُدثت اهداف البحث التي تمثلت بالمخطط الفرضي وتبلور عنه صياغة الفرضيات التي قيست بالبرنامج الاحصائي المتقدم"نمذجة المعادلات الهيكلية بطريقة المربعات

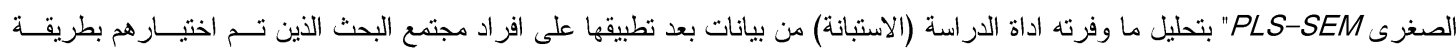

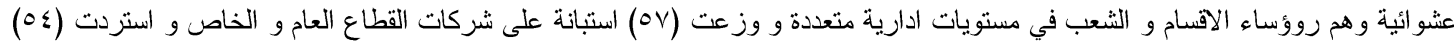

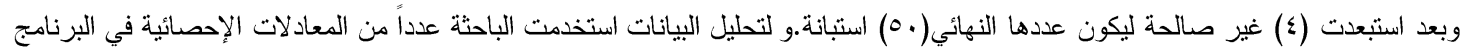

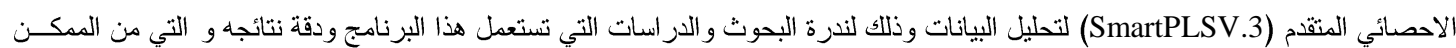
ان تساعد في التوصل الى استتاجات موضو عية ودقيقة، فضلا عن استعمال برنامج (SPSSv22) لتقويم أداة القياس.

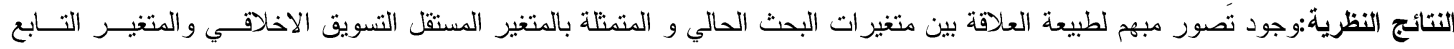
التوازن الاستر اتيجي. النتائج العملية:إنّ أهم النتائج العملية التي توصل اليها البحث تتلخص بوجود علاقة تأثير مبانشرة موجبة ومعنوية بين التسويق الاخلاقي التــوازن الاستر اتيجي لكلا القطاعين مع تقوق القطاع الخاص في نسبة هذه العلاقة. قيمة البحث و أصالته:تتمثل قيمة البحث بإرساء قو اعد معرفية و مفاهيمية لمتغير اتها من خلال توضيح علاقة التأثير الموجبة المباتشرة والمعنوية

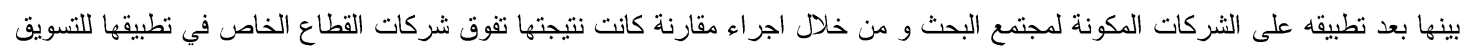

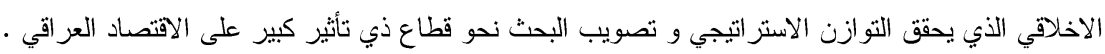

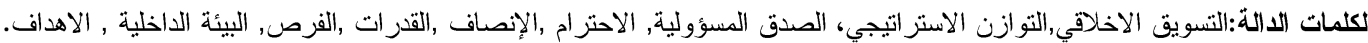

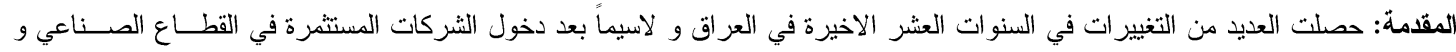

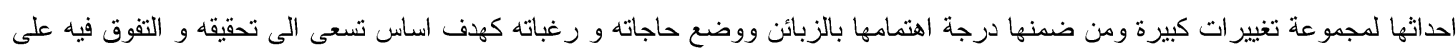

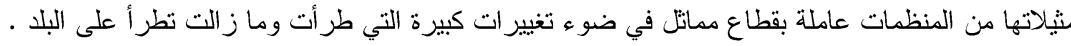

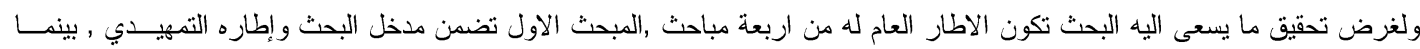

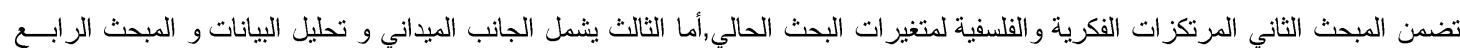

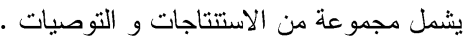

1- مدخل البحث و إطاره التمهيدي

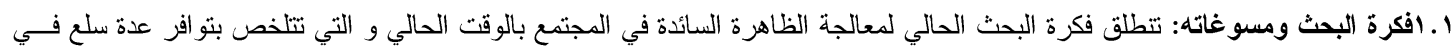

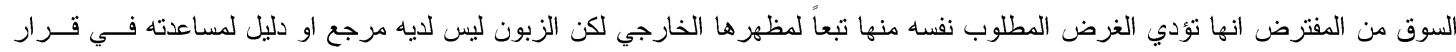

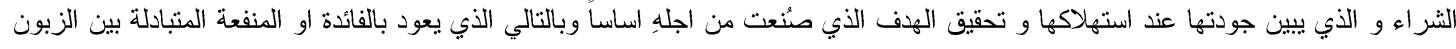

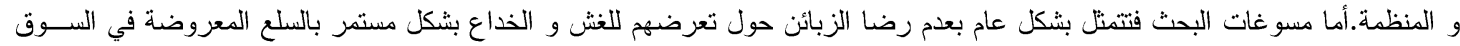

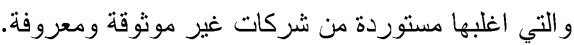
r.ا مشكلة البحث: ان السوق في العراق من الاسواق التي ظهر فيها مفهوم الاستثمار حديثاً و اصبح هناك قطاعات (العام و الخاص و والمختلط)

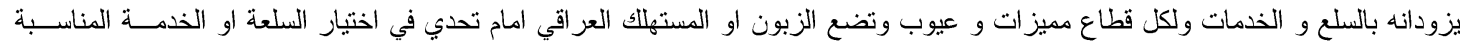

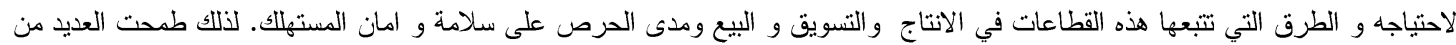

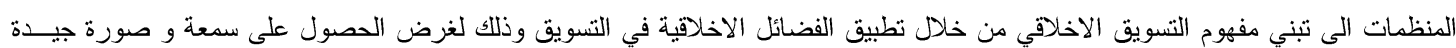

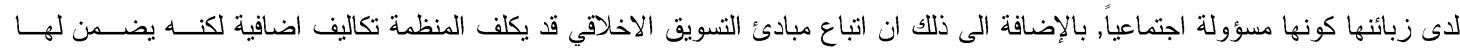
بالمقابل المكانة الجيدة في السوق , ويجب على المنظمة ان تحافظ على هذه المكانة من خلال الموازنة بين مدخلاتها و مخرجاتها في ظل اليئــة 
المتغيرة وما يتخلاها من فرص و تهديدات يجب ان تستغلها في لتحقيق اهدافها بناءٌ على قدر اتها الداخلية و ان تتلاءم مــع الانظمــة و القـو انين السائدة في البلا المنتج لكي تتصف بالثر عية وفي الوقت نفسه ان تتميز عن مثيلاتها من المنظمات.

وفي ضوء مميزات متغير ات البحث التي ذكرت يمكن صياغة المشكلة العامة كالآتي:

(هل للتسويق الاخلاقي تأثير في التوازن الاستراتيجي)؟ و بالانطلاق من المشكلة العامة يمكن تحديد مشكلة البحث من خلا مجموعة خاصة من

الاسئلة و هي:

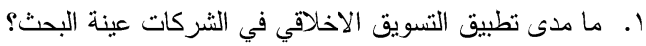

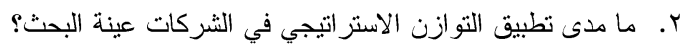

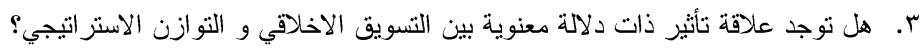

1. أهداف البحث: تتجسد اهداف البحث كالاتي:-

1. معرفة مدى تبني السوق العر اقي و الذي يتمثل بشريحة الشركات الخاصة و العامة عينة البحث في تطبيق متغير اتها.

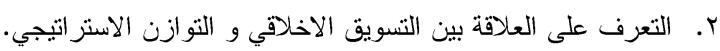

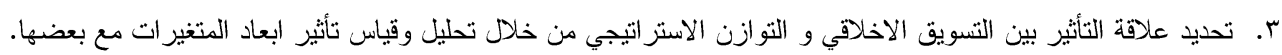

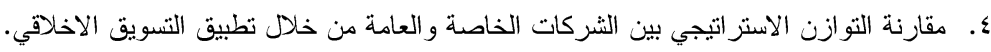

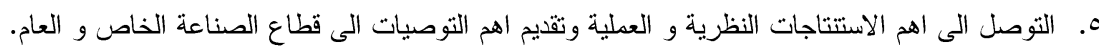

ـ أهمية البحث: تتمثل اهمية البحث كالاتي:-

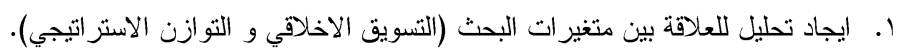

r. . يتصف موضوع البحث بحداثته على مستوى العالم العربي و العراق على حد علم كل من (المشرف) و (الباحثة) بعد الاطلاع على الدراسات

و البحوث العلمية عبر شبكة الانترنت.

r. يستهذف البحث قطاعاً حيوياً ومهماً في العراق و هو قطاع الصناعة على المستوى الخاص و العام لها له من مساهمة كبيرة في دعم اقتصاد

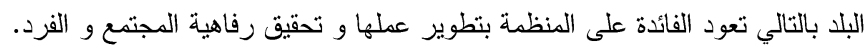

ع. تجذب المشكلة التي يعرضها البحث اهتمام المنظمات عن دور عمل هذه المتغيرات في المساهمة في تحقيق الكفاءة والفاعلية في انتاجها.

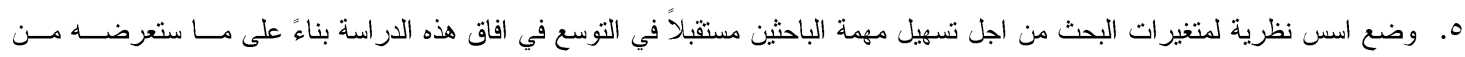

توصيات.

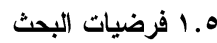

1. التسويق الأخلاقي له تأثير معنوي موجب في التوازن الاستر اتيجي على مستوى شركات القطاع الخاص و العام.

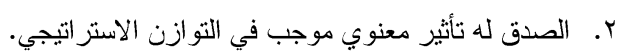

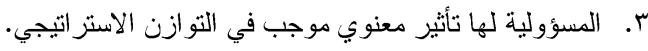

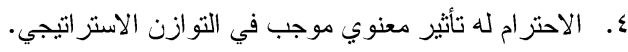

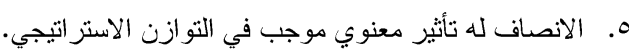

1. 1.1 المخطط الفرضي للبحث

هو عبارة عن رسم توضيحي يبين طبيعة العلاقة المفترضة التي يقوم عليه البحث إذ يصور علاقة المتغيرات مع بعضها بصورة مبسطة اكثر.

و الشكل رقم (1) يوضح المخطط الفرضي للعلاقة بين متغيرات البحث. 


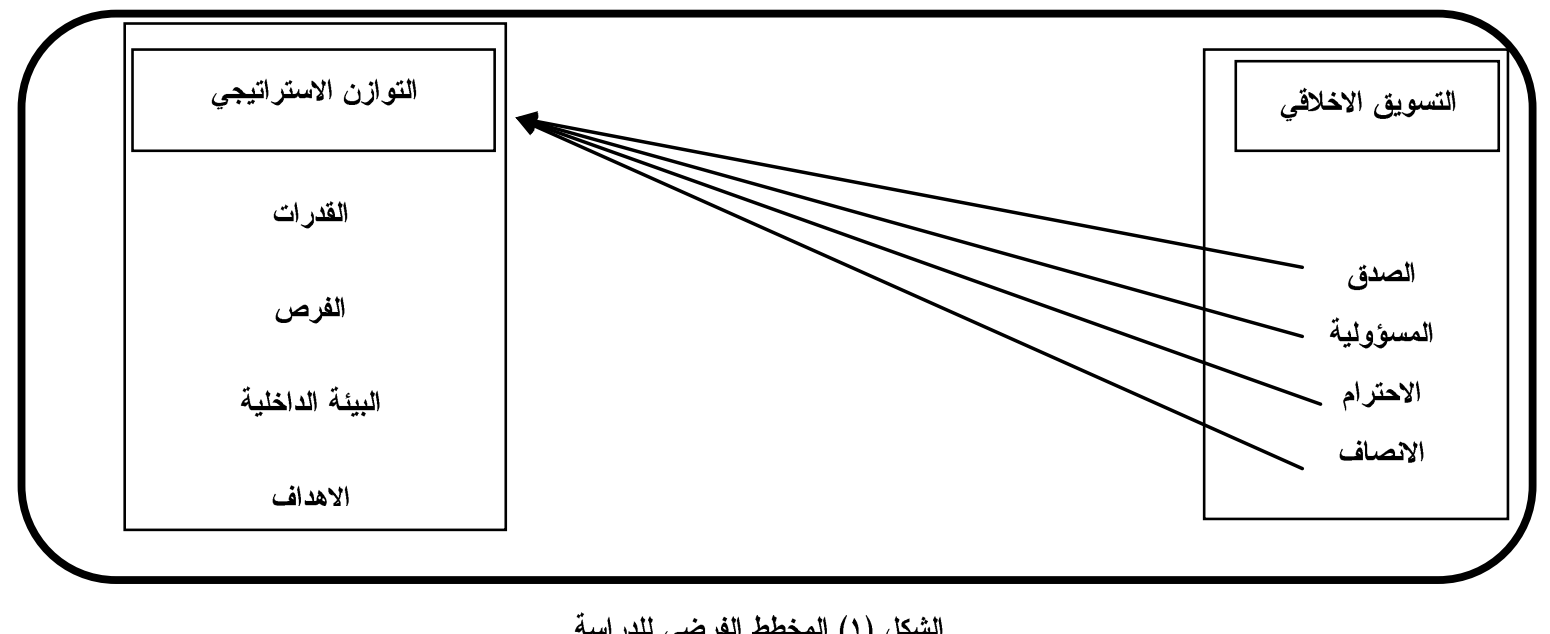

الشكل (1) المخطط الفرضي للار اسة

المصدر : من اعداد الباحثة

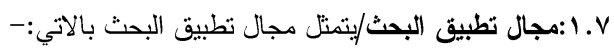

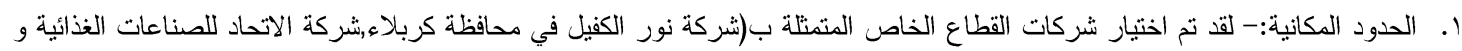

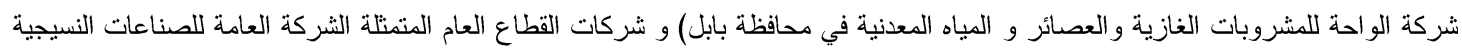

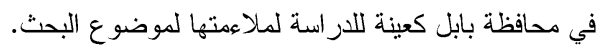

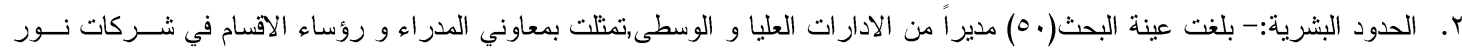
الكفيل و الاتحاد و الواحة و معمل النسيج.

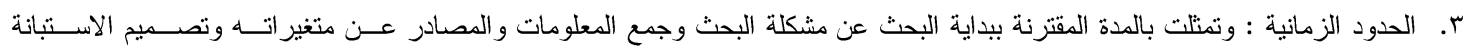

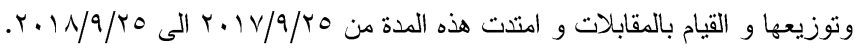

$$
\text { r- المرتكزات الفكرية و الفلسفية للتسويق الاخلاقي و التوازن الاستراتيجي }
$$

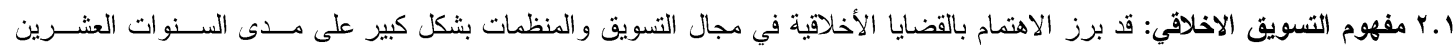

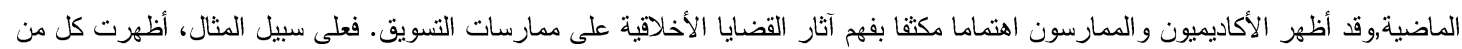

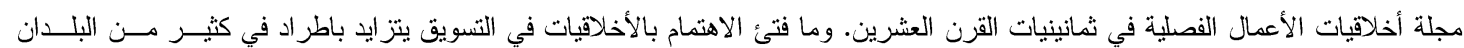
الأسيوية

ولا سيما في القرن الحادي و العشرين ويرجع ذلك أساسا إلى ارتفاع النشاط الاستهلاكي و إنتاج زبائن متطورين يدققون ممارسات التسويق أكثر من أي وقت مضــى [1]. و ادناه جدول (1) يستعرض مفهوم التسويق الاخلاقي من وجهة نظر عدد من الباحثين و المفكرين.

جدول (1) مفهوم التسويث الاخلافي من وجهة نظر عدد من الباحثين والمفكرين

\begin{tabular}{|c|c|c|}
\hline 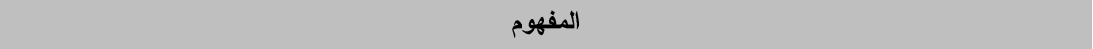 & 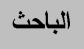 & $ت$ \\
\hline 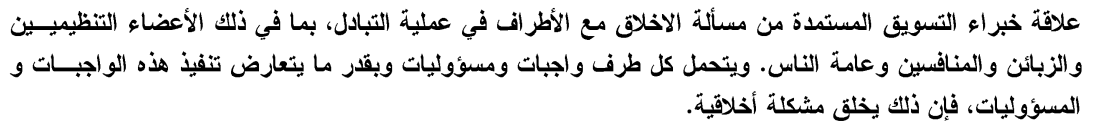 & [2] & 1 \\
\hline 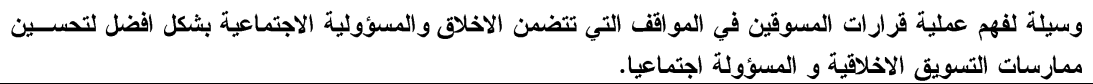 & [3] & r \\
\hline سلاح (أداة ) فعال/ فعالة لتطوير التسويق من خلال الجاتب الاخلاقي مع بضعة أفكار اخرى. & [4] & $r$ \\
\hline 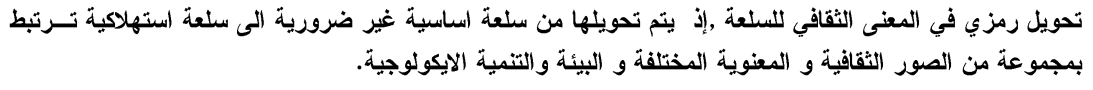 & [5] & $\varepsilon$ \\
\hline 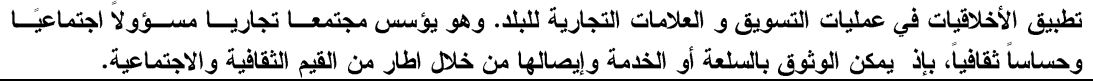 & [1] & - \\
\hline مجموعة من الممارسات التي تسعى الى تعزيز القيم الاخلاقية للمنظمات إذ يتم جذب الزيون للثر اء من هكذا منظمات. & [6] & 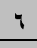 \\
\hline المليل على بيان الاحتياجات الفردية داخل المجتمع وإظهار المسؤولية عن الأعمال التجارية ، ومشاركته من خلا دعــم & [7] & $\mathrm{v}$ \\
\hline
\end{tabular}

المصدر:اعداد الباحثة بالاعتماد على المصادر الواردة فيه. 
ابعاد التسويق الاخلاقي: r. r

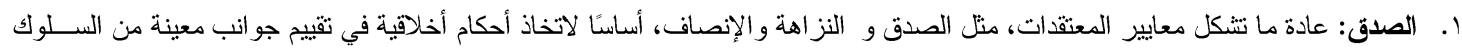

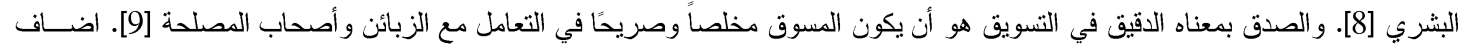

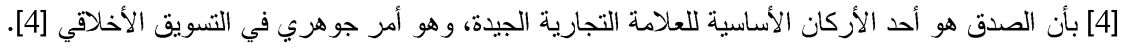

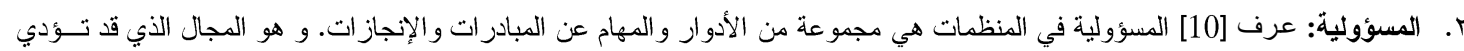
فيه الخبرات المختلفة في تتفيذ عزوفيذ الوظائف بصورة متباينة إلى ظهور توقعات اخلاقية مختلفة [10]. و وضئ اوضح [9] ان مدر اء التسويق يتحملون مسؤولية مر اقبة نتـائج قــرار اتهم

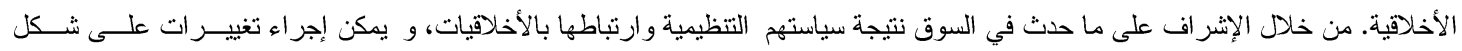
بروتوكو لات صنع القزار في المستقبل [9].

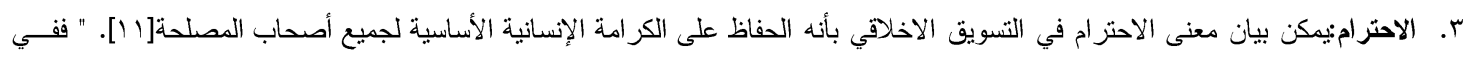

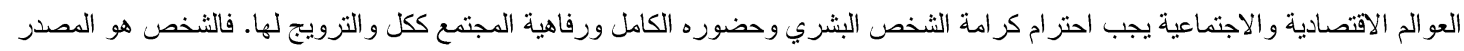

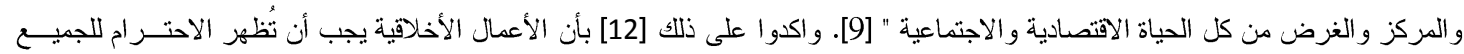

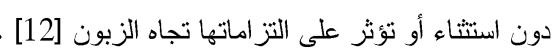

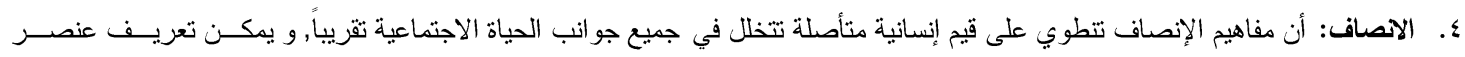

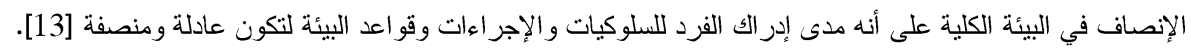

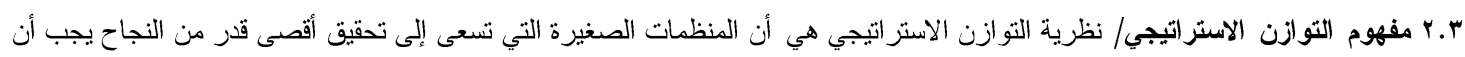

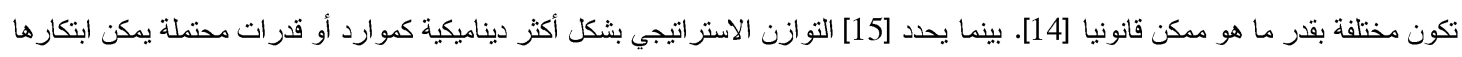

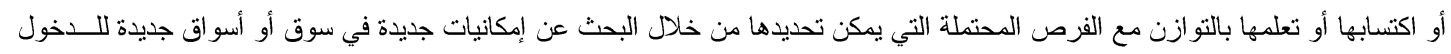

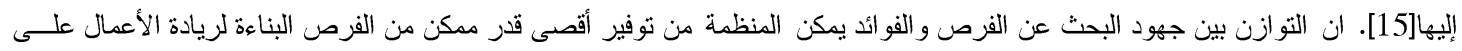

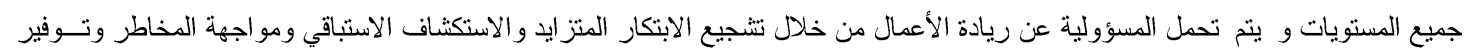

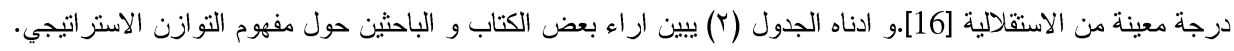

جدول(ץ) مفهوم التوازن الاستر اتيجي بحسب آراء بعض الكتّاب و الباحثين

\begin{tabular}{|c|c|c|}
\hline المفهوم & الباحث & ت \\
\hline 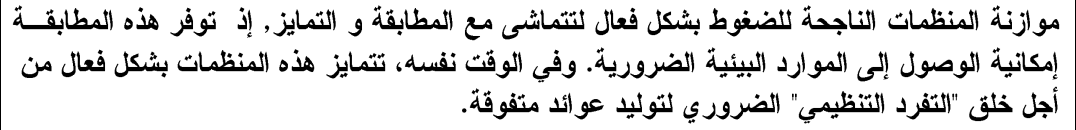 & [17] & 1 \\
\hline التمايز والمطابقة. منانها أن تقود المدراء للسعي إلى الهوية المتفردة التي تمثل الحل التوفيقي المثالي بين & [18] & $r$ \\
\hline مزج السوق و التقنيات المؤسسية للمحاولة بإيجاد نهج متوازن في المنظمات. & [19] & $r$ \\
\hline التوازن بين الموارد الداخلية القائمة و الفرص الخارجية. & {$[15]$} & $\varepsilon$ \\
\hline 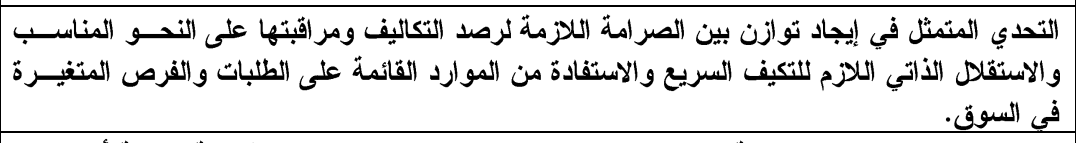 & [16] & 0 \\
\hline 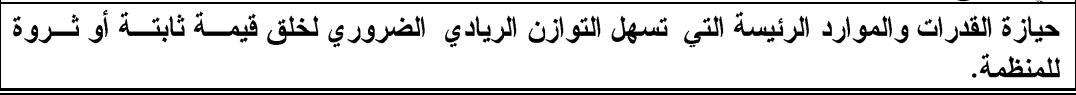 & [20] & 7 \\
\hline
\end{tabular}

$$
\begin{aligned}
& \text { من اعداد الباحثة بالاستناد الى ما ورد فيه }
\end{aligned}
$$

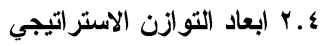

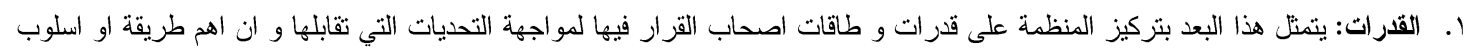

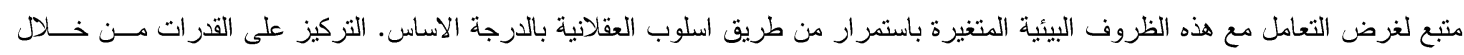

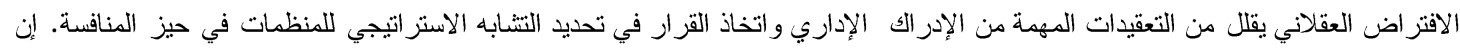

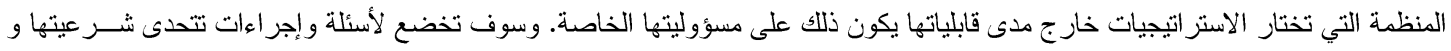

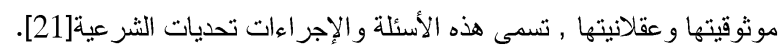

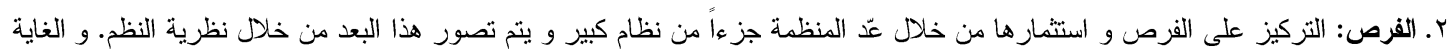

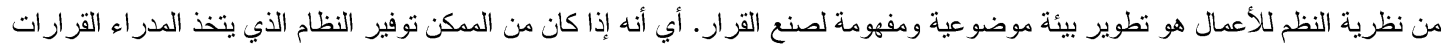




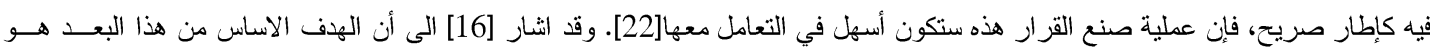

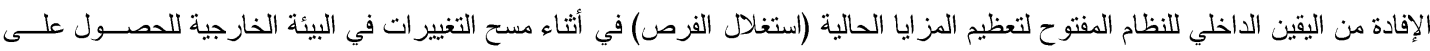

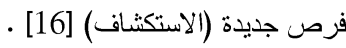

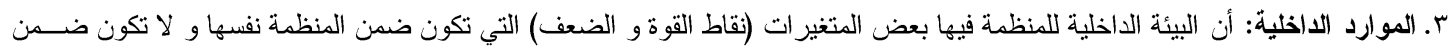

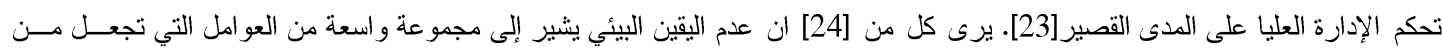

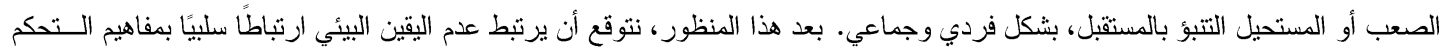

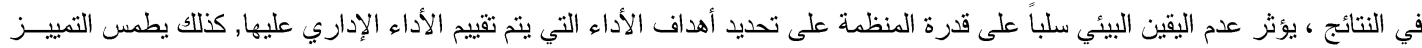

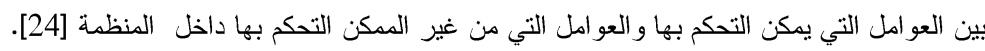

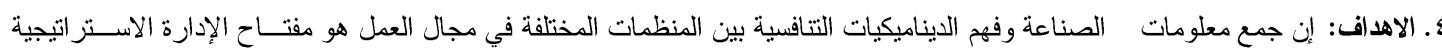

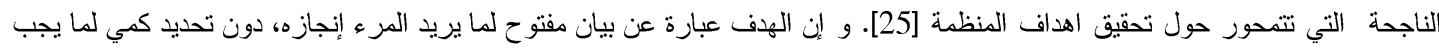

تحقيقه و عدم وجود معايير زمنية للإنجاز [23].

r- الجانب الميداني وتحليل البيانات

1. ا ب التحليل الوصفي لمتغيرات البحث

للتحليل الوصفي بما يتضمنه من مقاييس النزعة المركزية ومقاييس التشتت أثز مهم في عرض وتلخيص البيانات التي جمعتها

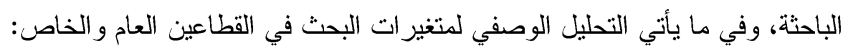
1. التحليل الوصفي لمتغير التسويق الأخلاقي في القطاع العام

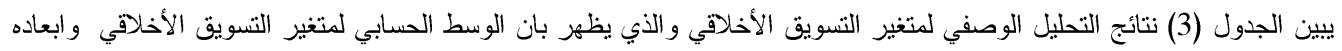
الاربعة قد بلغت اكثر من (5) وبذلك فهي تتجاوز الوسط الفرضي البالغ (4) لمقياس ليكرت السباعي مما يدل على انتثار المتغير وجميع ابعاده في المنظمات قيد الدراسة، كذلك فقد اظهرت النتائج انخفاض الانحراف المعياري لفقرات الاستبانة كافة وهذا يدل على انسجام في اجابات

جدول (攵) التحليل الوصفي لمتغير التسويق الأخلافي

\begin{tabular}{|c|c|c|c|c|}
\hline الفقرة & ادنى قيمة & اقصى قِيمة & الوسط الحسابي & الاتحراف المعياري \\
\hline$\overline{\mathrm{HO1}}$ & 1.00 & 7.00 & $\overline{5.5465}$ & .69717 \\
\hline HO2 & 1.00 & 7.00 & 5.1395 & .68878 \\
\hline HO3 & 1.00 & 7.00 & 5.3953 & .80116 \\
\hline HO4 & 1.00 & 7.00 & 5.0930 & .77654 \\
\hline الصدق HO & 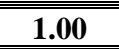 & 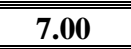 & 5.293575 & 0.740913 \\
\hline RES1 & $1 \overline{1.00}$ & 7.00 & 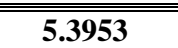 & 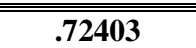 \\
\hline RES2 & 1.00 & 7.00 & 5.0581 & .74130 \\
\hline RES3 & 1.00 & 7.00 & 5.0116 & .72751 \\
\hline RES4 & 1.00 & 7.00 & 5.3605 & .78084 \\
\hline المسؤولية & (1.00 & $\begin{array}{l}7.00 \\
\end{array}$ & 5.206375 & 0.74342 \\
\hline RS1 & 1.00 & 7.00 & (5.4535 & ".71385 \\
\hline RS2 & 1.00 & 7.00 & 5.0349 & .65883 \\
\hline RS3 & 1.00 & 7.00 & 5.0930 & .83494 \\
\hline RS4 & 1.00 & 7.00 & 5.0000 & .78215 \\
\hline الاحترام & 1.00 & $7 \overline{7.00}$ & 5.14535 & 0.747443 \\
\hline FA1 & 1 & 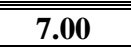 & (5.1628 & (185213 \\
\hline FA2 & 1.00 & 7.00 & 5.9186 & .72299 \\
\hline FA3 & 1.00 & 7.00 & 5.1512 & .83338 \\
\hline FA4 & 1.00 & 7.00 & 5.9186 & .89725 \\
\hline الانصاف & 1.00 & 7.00 & 5.5378 & 0.826438 \\
\hline التسويق الأخلاقي EM & 1.00 & 7.00 & 5.295775 & 0.764554 \\
\hline
\end{tabular}


r ا التحليل الوصفي لمتغير التوازن الاستراتيجي في القطاع العام

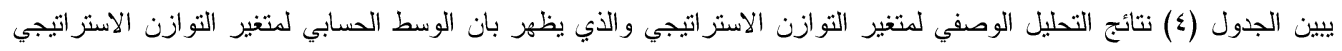

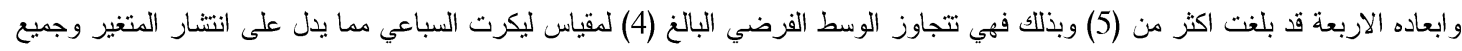

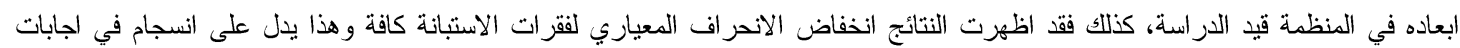
المستجيين.

جدول (ع) التحيل الوصفي لمتغير التوازن الاستر اتيجي

\begin{tabular}{|c|c|c|c|c|}
\hline الفقرة & ادنى قيمة & اقصى قيمة & الوسط الحسابي & الانحراف المعياري \\
\hline CA1 & 1.00 & 7.00 & 5.5814 & .62243 \\
\hline CA2 & 1.00 & 7.00 & 5.2442 & .70186 \\
\hline CA3 & 1.00 & 7.00 & 5.1163 & .84601 \\
\hline CA4 & 1.00 & 7.00 & 5.1163 & .75799 \\
\hline القدرات & $\overline{1.00}$ & 7.00 & 5.26455 & (2.732073 \\
\hline OP1 & 1.00 & 7.00 & 5.0116 & .65966 \\
\hline OP2 & 1.00 & 7.00 & 5.2287 & .48779 \\
\hline OP3 & 1.00 & 7.00 & 5.1163 & .75799 \\
\hline OP4 & 1.00 & 7.00 & 5.1279 & .74828 \\
\hline الفرص & 1.00 & "7.00 & 5.121125 & $\overline{0.66343}$ \\
\hline IE1 & 1.00 & 7.00 & 5.1744 & ב.72261 \\
\hline IE2 & 1.00 & 7.00 & 5.2326 & .73042 \\
\hline IE3 & 1.00 & 7.00 & 5.2465 & .47495 \\
\hline IE4 & 1.00 & 7.00 & 5.1512 & .81915 \\
\hline البيئة الداخلية & 1.00 & 7.00 & 5.201175 & 0.686783 \\
\hline GO1 & $\overline{1.00}$ & 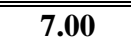 & 5.9419 & (269205 \\
\hline GO2 & 1.00 & 7.00 & 5.9884 & .84706 \\
\hline GO3 & 1.00 & 7.00 & 5.2326 & .73042 \\
\hline GO4 & 1.00 & 7.00 & 5.9767 & .75110 \\
\hline GO5 & 1.00 & 7.00 & 5.0814 & .85701 \\
\hline الاهداف & 1.00 & "7.00 & 5.6442 & 0.775528 \\
\hline التوازن الاستراتيجي & 1.00 & 7.00 & 5.307763 & 0.70858 \\
\hline
\end{tabular}

SPSS المصدر: مخرجات برنامج r. التحليل الوصفي لمتغير التسويق الأخلاقي في القطاع الخاص

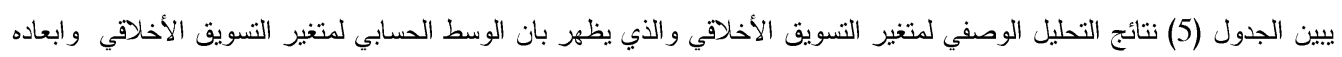
الاربعة قد بلغت اكثر من (5) وبذلك فهي تتجاوز الوسط الفرضي البالغ (4) لمقياس ليكرت السباعي مما يدل على انتثار المتغير وجميع ابعاده

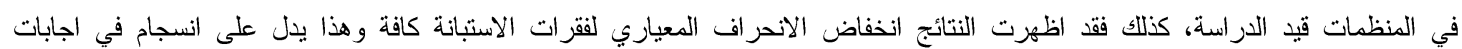
المستجبيين.

جدول (•) التحليل الوصفي لمنغير التسويث الأخلاقي

\begin{tabular}{|c|c|c|c|c|}
\hline الفقرة & قيمة & قاقصى & الحسابي & الانعراف المعياري \\
\hline HO1 & 1.00 & 7.00 & 5.8465 & 69717 \\
\hline HO2 & 1.00 & 7.00 & 6.1395 & .68878 \\
\hline HO3 & 1.00 & 7.00 & 5.9953 & .80116 \\
\hline HO4 & 1.00 & 7.00 & 6.0930 & .77654 \\
\hline الصدق HO & 1.00 & 7.00 & 6.018575 & 0.740913 \\
\hline RES1 & $\begin{array}{l}1.00 \\
\end{array}$ & $\begin{array}{l}7.00 \\
\end{array}$ & " 5.8953 & ".72403 \\
\hline RES2 & 1.00 & 7.00 & 6.0581 & .74130 \\
\hline RES3 & 1.00 & 7.00 & 6.0116 & .72751 \\
\hline RES4 & 1.00 & 7.00 & 5.9605 & .78084 \\
\hline المسوؤلية & 101.00 & $\overline{70.00}$ & 5.981375 & 0.74342 \\
\hline RS1 & 1.00 & 7.00 & 5.7695 & ".71385 \\
\hline RS2 & 1.00 & 7.00 & 6.0349 & .65883 \\
\hline
\end{tabular}




\begin{tabular}{|c||c||c||c||c||}
\hline RS3 & 1.00 & 7.00 & 6.0930 & .83494 \\
\hline RS4 & 1.00 & 7.00 & 6.0000 & .78215 \\
\hline \hline FA1 & 1.00 & 7.00 & 5.97435 & $\mathbf{0 . 7 4 7 4 4 3}$ \\
\hline \hline FA2 & 1.00 & 7.00 & 6.1628 & .85213 \\
\hline FA3 & 1.00 & 7.00 & 6.9186 & .72299 \\
\hline FA4 & 1.00 & 7.00 & 6.1512 & .83338 \\
\hline \hline FAn & 1.00 & 7.00 & 5.9186 & .89725 \\
\hline \hline الانصويق الأخلاقي & 1.00 & 7.00 & 6.2878 & $\mathbf{0 . 8 2 6 4 3 8}$ \\
EM & 1.00 & 7.00 & 6.065525 & $\mathbf{0 . 7 6 4 5 5 4}$ \\
\hline
\end{tabular}

SPSS المصدر : مخرجات برنامج

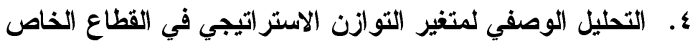

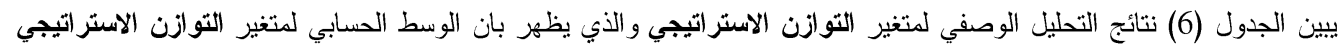

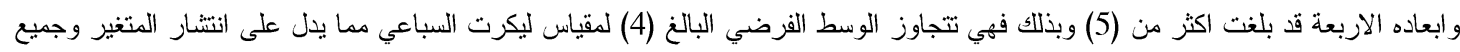

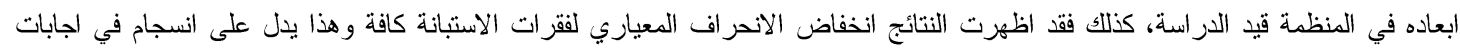

جدول (†) التحليل الوصفي لمتغير التوازن الاستراتيجي

\begin{tabular}{|c|c|c|c|c|}
\hline الفقرة & ادنى قيمة & اقصى قيمة & الوسط الحسابي & الانحراف المعياري \\
\hline CA1 & 1.00 & 7.00 & 5.9814 & .62243 \\
\hline CA2 & 1.00 & 7.00 & 5.9442 & .70186 \\
\hline CA3 & 1.00 & 7.00 & 6.1163 & .84601 \\
\hline CA4 & 1.00 & 7.00 & 6.1163 & .75799 \\
\hline القدرات & 1.00 & 7.00 & 6.03955 & 0.732073 \\
\hline OP1 & 1.00 & 7.00 & 6.0116 & .65966 \\
\hline OP2 & 1.00 & 7.00 & 5.7287 & .48779 \\
\hline OP3 & 1.00 & 7.00 & 6.1163 & .75799 \\
\hline OP4 & 1.00 & 7.00 & 6.1279 & .74828 \\
\hline الفرص & 1.00 & 7.00 & 5.996125 & 0.66343 \\
\hline IE1 & 1.00 & 7.00 & 6.1744 & .72261 \\
\hline IE2 & 1.00 & 7.00 & 5.7326 & .73042 \\
\hline IE3 & 1.00 & 7.00 & 5.9465 & .47495 \\
\hline IE4 & 1.00 & 7.00 & 5.8512 & .81915 \\
\hline البيئة الداخلية & 1.00 & 7.00 & 5.926175 & 0.686783 \\
\hline GO1 & 1.00 & 7.00 & 5.9419 & .69205 \\
\hline GO2 & 1.00 & 7.00 & 5.9884 & .84706 \\
\hline GO3 & 1.00 & 7.00 & 6.0326 & .73042 \\
\hline GO4 & 1.00 & 7.00 & 5.9767 & .75110 \\
\hline GO5 & 1.00 & 7.00 & 5.8814 & .85701 \\
\hline الاهداف & 1.00 & 7.00 & 5.9642 & 0.775528 \\
\hline التوازن الاستراتيجي & 1.00 & 7.00 & 5.981513 & 0.714454 \\
\hline
\end{tabular}




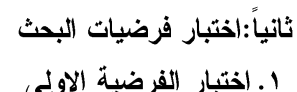

نصت الفرضية الاولى على ان "التسويق الأخلاقي له تأثير معنوي موجب في التوازن الاستراتيجي " ولغرض اختبار هذه الفرضية

تم بناء الانموذج الهيكلي وكما يظهر في الثنكل (2).

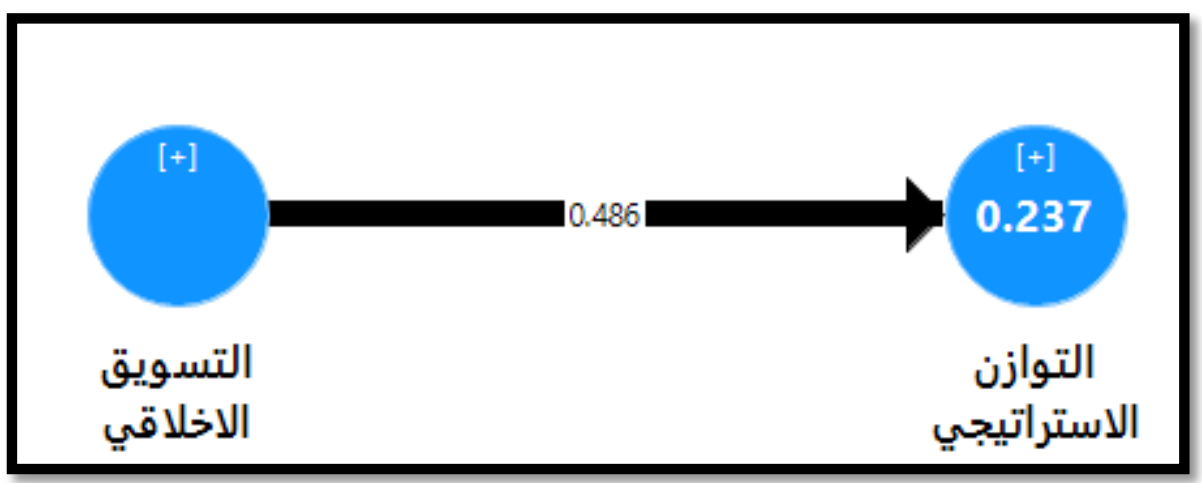

شكل (ץ) الأموذج الهيكلي لاختبار الفرضية الاولى في القطاع العام

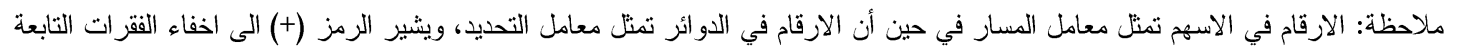

$$
\text { للمتغير بسبب انتفاء الحاجة لها في تقيبي الانموذج الهيكلي. }
$$

SmartPLS المصدر: مخرجات برنامج

جدول (V) نتائج تقييم الانموذج الهيكلي الخاص بالفرضية الاولى في القطاع العام

\begin{tabular}{|c|c|c|c|c|c|c|c|c|c|c|}
\hline |المعدل & معامل التحديد R2 & || | حجم التأثير & |النتيجة || & p Value & t Value & | معامل المسار & VIF & المسار & الفرضية & جودة المطابقة \\
\hline 0.236 & 0.237 & 0.643 & قبول & 0 & $\mid 212.791$ & 0.486 & 1 & ETM $\rightarrow$ SB & 1 & $\overline{0.071}$ \\
\hline
\end{tabular}

SmartPLS المصدر: مخرجات برنامج

أظهرت نتائج التحليل بأن معيار الجذر التربيعي المتوسط الموحد (SRMR) قد بلغت قيمته للنموذج الهيكلي (0.071) ولذا فهو يحقق

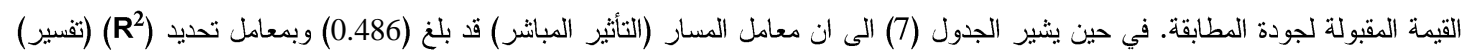

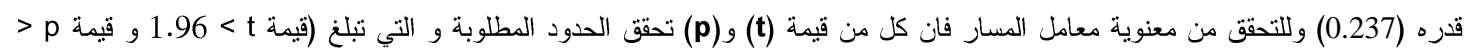

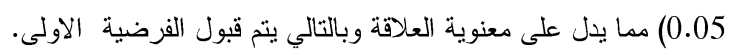

لغرض اختبار الفرضيات المنبتقة من الفرضية الاولى تم بناء الانموذج الهيكلي وكما يظهر في الثنكل (3). 


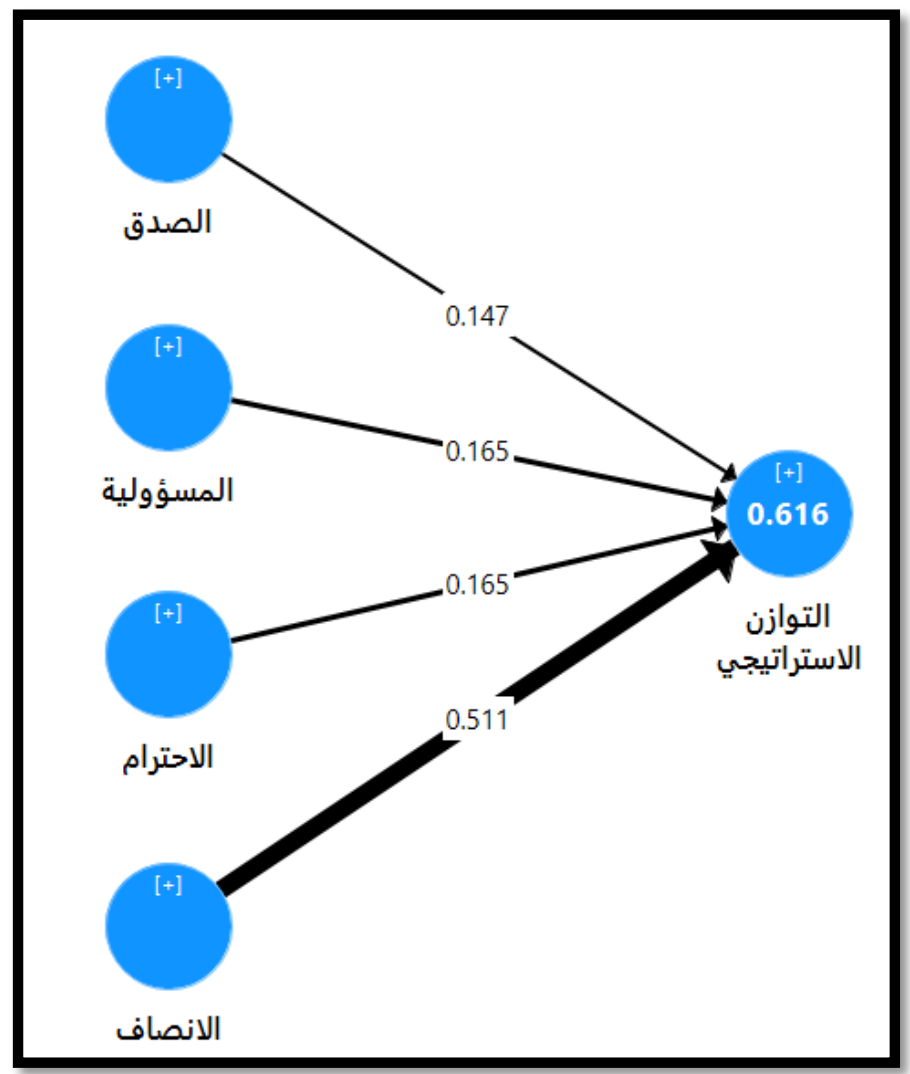

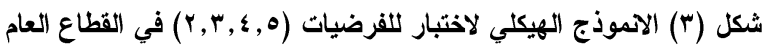

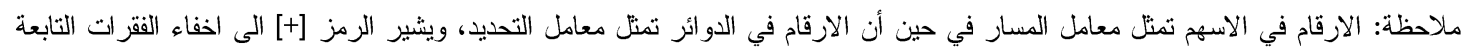

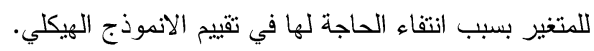
المصدر: مخرجات برنامج SmartPLS

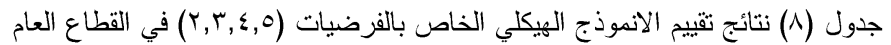

\begin{tabular}{|c|c|c|c|c|c|c|c|c|c|c|}
\hline $\begin{array}{l}\mathbf{R}^{2} \\
\end{array}$ & $\begin{array}{c}\text { معامل التحديد } \\
\mathbf{R}^{2} \\
\end{array}$ & حجم التأتثير & |النتيجة & $\begin{array}{c}\mathbf{p} \\
\text { Value } \\
\end{array}$ & $\begin{array}{c}t \\
\text { Value }\end{array}$ & المسار & VIF & المسار & الفرضية & جودة المطابقة \\
\hline \multirow{4}{*}{0.612} & \multirow{4}{*}{0.616} & $\overline{0.043}$ & رفض & 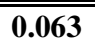 & 0.858 & 0.147 & 2.06 & $\mathrm{HO} \rightarrow \mathrm{SB}$ & $\bar{r}$ & \multirow{4}{*}{0.078} \\
\hline & & 0.016 & رفض & 0.336 & 0.962 & 0.165 & 1.819 & $\mathbf{R E} \rightarrow \mathbf{S B}$ & $r$ & \\
\hline & & 0 & رفض & 0.959 & 0.052 & 0.165 & 1.863 & $\mathbf{R S} \rightarrow \mathbf{S B}$ & $\varepsilon$ & \\
\hline & & 0.017 & قبول & 0.002 & 2.564 & 0.511 & 2.334 & $\mathbf{F A} \rightarrow \mathbf{S B}$ & 0 & \\
\hline
\end{tabular}

SmartPLS المصدر: مخرجات برنامج

أظهرت نتائج التحليل بأن معيار الجذر التربيعي المتوسط الموحد (SRMR) قد بلغت قيمته للنموذج الهيكلي (0.078) ولذا فهو يحقق القيمة

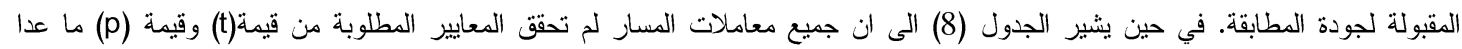

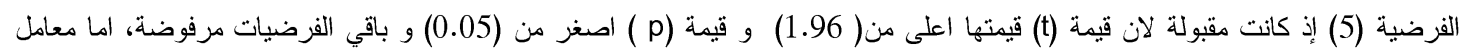
التحديد فكانت قيمته (60\%).

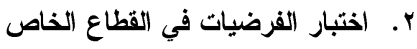

نصت الفرضية الاولى على ان "التسويق الأخلاقي له تأثير معنوي موجب في التوازن الاستراتيجي " ولغرض اختبار هذه الفرضية تم بناء

الانموذج الهيكلي وكما يظهر في الثكل (4). 


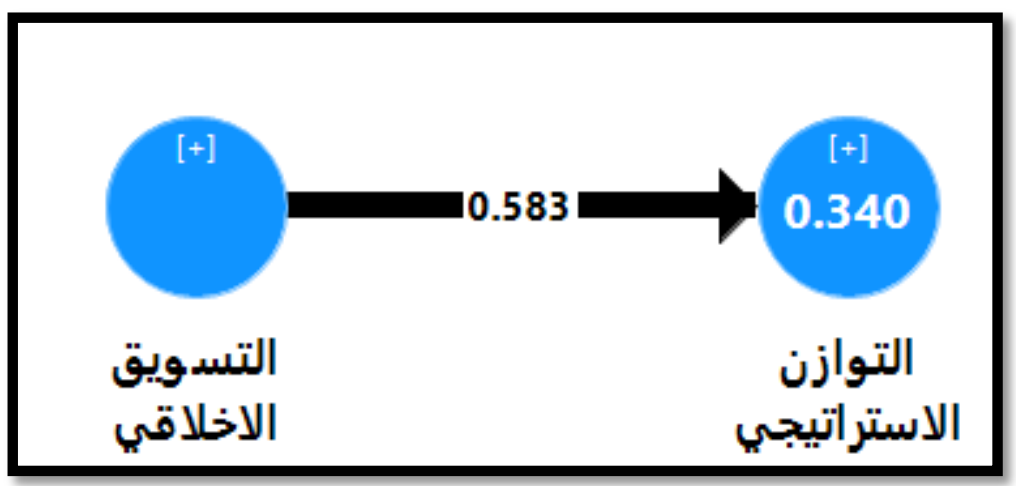

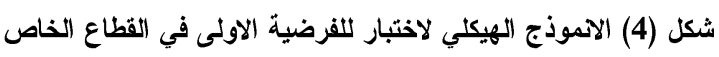

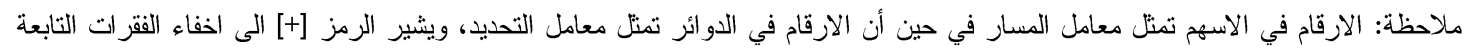

$$
\text { للمتغير بسبب انتفاء الحاجة لها في تقييم الانموذج الهيكلي. }
$$

SmartPLS المصدر: مخرجات برنامج

جدول (9) نتائج تقييم الانموذج الهيكلي الخاص بالفرضية الاولى في القطاع الخاص

\begin{tabular}{|c|c|c|c|c|c|c|c|c|c|c|}
\hline المعدل & Rع معل التحديد & حجم التأثير f & |النتيجة & p Value & t Value & معامل المسار & VIF & المسار & | الفرضية | & جودة المطابقة \\
\hline 0.384 & 0.391 & 0.643 & قبول & $\mathbf{0}$ & 16.711 & 0.583 & 1 & ETM $\rightarrow$ SB & 1 & 0.071 \\
\hline
\end{tabular}

SmartPLS المصدر: مخرجات برنامج

أظهرت نتائج التحليل بأن معيار الجذر التربيعي المتوسط الموحد (SRMR) قد بلغت قيمته للنموذج الهيكلي (0.071) ولذا فهو يحقق

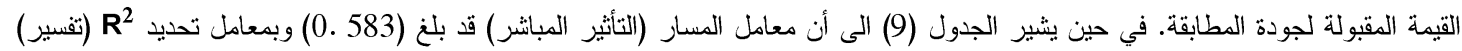

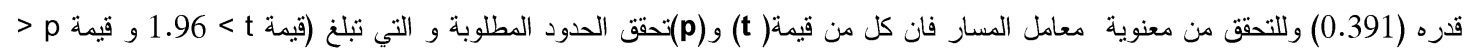

0.05) مما يدل على معنوية العلاقة وبالتالي يتم قبول الفرضية الاولى. لغرض اختبار الفرضيات (5,4,3,2) تم بناء الانموذج الهيكلي وكما

يظهر في الثكل (5). 


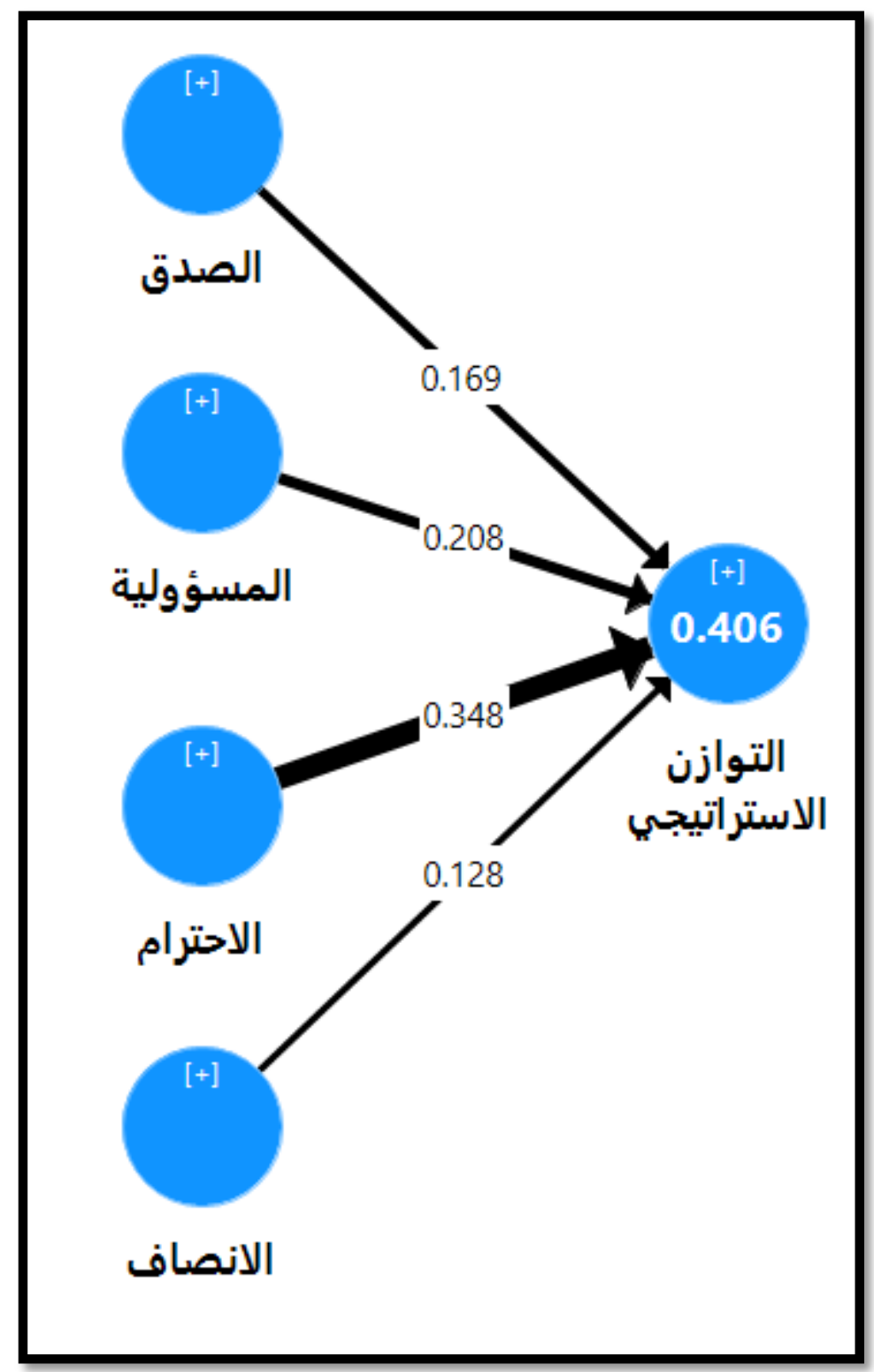

شكل (•) الانموذج الهيكلي لاختبار الفرضيات (5,4,3,2) في القطاع الخاص

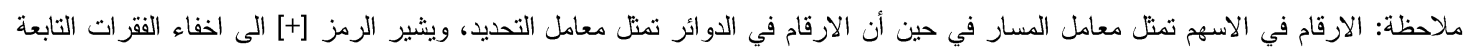
للمتغير بسبب انتفاء الحاجة لها في تقييم الانموذج الهيكلي. SmartPLS المصدر: مخرجات برنامج

جدول (• 1) نتائج تقييم الانموذج الهيكلي الخاص بالفرضيات (5,4,3,2) في القطاع الخاص

\begin{tabular}{|c|c|c|c|c|c|c|c|c|c|c|}
\hline $\begin{array}{c}\mathbf{R}^{2} \\
\text { المعدل }\end{array}$ & معامل التحديد & حجم التأثير & |النتيجة & $\begin{array}{c}\mathbf{p} \\
\text { Value }\end{array}$ & $\begin{array}{c}\mathrm{t} \\
\text { Value }\end{array}$ & المسارل & VIF & المسار & الفرضية & $\begin{array}{c}\text { المطابقة } \\
\text { SRMR } \\
\text { SRM }\end{array}$ \\
\hline \multirow{4}{*}{0.401} & \multirow{4}{*}{0.406} & 0.043 & رفض & 0.063 & 1.858 & 0.169 & 2.06 & $\mathrm{HO} \rightarrow \mathrm{SB}$ & $r$ & \multirow{4}{*}{0.078} \\
\hline & & 0.416 & قبول & 0.006 & 2.962 & 0.208 & 1.819 & $\mathrm{RE} \rightarrow \mathrm{SB}$ & $r$ & \\
\hline & & 0.652 & قبول & 0.009 & 3.052 & 0.348 & 1.863 & $\mathrm{RS} \rightarrow \mathrm{SB}$ & $\varepsilon$ & \\
\hline & & 0.007 & رفض & 0.572 & 0.564 & 0.128 & 2.334 & $\mathbf{F A} \rightarrow$ SB & 0 & \\
\hline
\end{tabular}

SmartPLS المصدر: مخرجات برنامج

أظهرت نتائج التحليل بأن معيار الجذر التربيعي المتوسط الموحد (SRMR) قد بلغت قيمته للنموذج الهيكلي (0.078) ولذا فهو يحقق القيمة

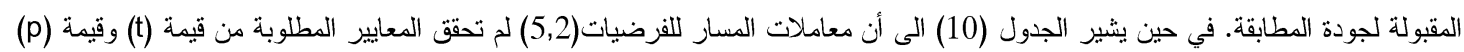


وبالتالي نرفض هذه الفرضيات، واما الفرضيات(4,3) فقد حققت المعايير المطلوبة وبالتالي يتم قبول هذه الفرضيات اما معامل التحديد فكانت قيمته (40\%).

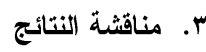

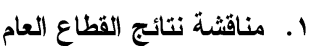

من خلال نتائج اختبار الفرضيات التي توصلت اليها الباحثة والتي يلخصها الجدول (11) يمكن مناقتنة هذه النتائج وفق الجوانب الآتية: جدول (11) ملذص نتائج اختبار فرضيات البحث في القطاع العام

\begin{tabular}{|c|c|c|c|}
\hline النتيجة & التأثير & الفرضية & 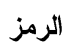 \\
\hline قبيول & 0.486 & |التسويق الأخلاقي له تأثير معنوي موجب في التوازن الاستراتيجي. & 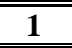 \\
\hline رفض & 0.147 & |الصدق له تأثيّير معنوي موجب في التوازن الاستراتيجي. & 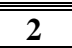 \\
\hline رفض & 0.165 & المسؤولية لها تأثير معنوي موجب في التوازن الاستراتيجي. & 3 \\
\hline رفض رض & 0.165 & |الاحترام له تأثير معنوي موجب في التوازن الاستر اتيجي. & 4 \\
\hline قبول & 0.511 & |الانصاف له تأثير معنوي موجب في التوازن الاستراتيجي. & 5 \\
\hline
\end{tabular}

المصدر: اعداد الباحثة وفقاً لنتائج البحث.

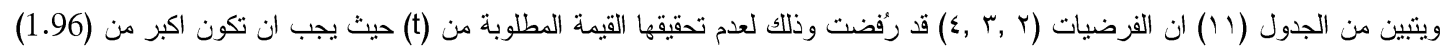

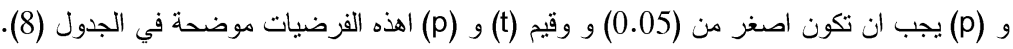
التأثثر المباشر لمتغير التسويق الأخلافي في التوازن الاستراتيجي في القطاع العام:

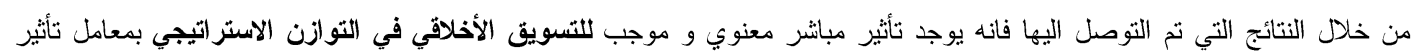

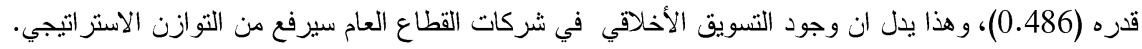

r. r. مناقشة نتائج القطاع الخاص

من خلال نتائج اختبار الفرضيات التي نوصلت اليها الباحثة والتي يلخصها الجدول (12) يمكن مناقثة هذه النتائج وفق الجوانب الاتية:

جدول (Y l) ملغص نتائج اختبار فرضيات البحث في القطاع الخاص

\begin{tabular}{|c|c|c|c|}
\hline النتيجة & التأثير & الفرضية & 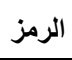 \\
\hline قبول & 0.583 & |التسويق الأخلافى له تأثير معنوي موجب في التوازن الاستر اتيجي. & 1 \\
\hline رفض & 0.169 & |الصدق له تأثير موجب معنوي في التوازن الاستر اتيجي. & 2 \\
\hline قبول & 0.208 & المسؤولية لها تأثير معنوي موجب في التوازن الاستر اتيجي. & 3 \\
\hline قبول & 0.348 & الاحتر ام له تأثير معنوي موجب في التوازن الاستر اتيجي. & 4 \\
\hline رفض & 0.128 & |الاتصاف له تأثير معنوي موجب في التوازن الاستر اتيجي. & 5 \\
\hline
\end{tabular}

المصدر: اعداد الباحثة وفقاً لنتائج البحث.

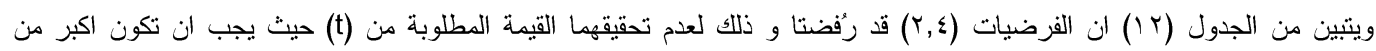

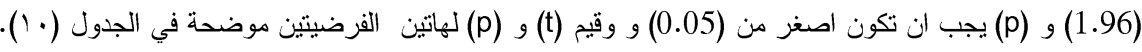

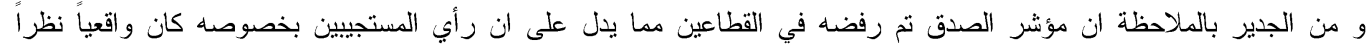

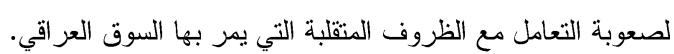

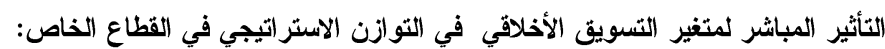

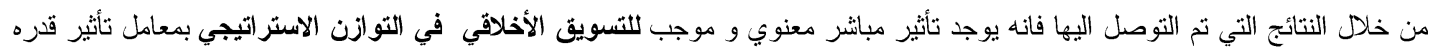

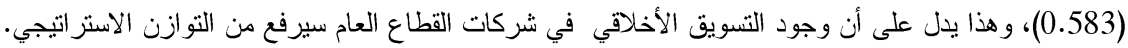

ع - الاستنتاجات و التوصيات

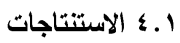

ا. أن اتباع نهج التسويق الاخلاقي في المنظمات قد يرفع من مستوى التو ازن الاستر اتيجي نسيباً, وكانت المقارنة بين القطاعين هو تفوق عينــة

القطاع الخاص على العام فكانت هذه العلاقة اعلى نسبيا.

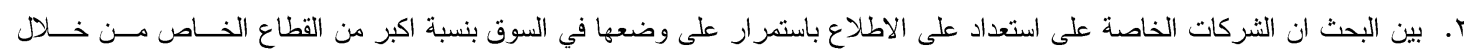

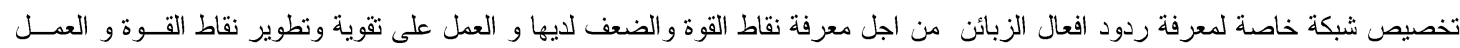

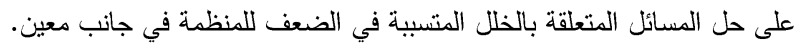




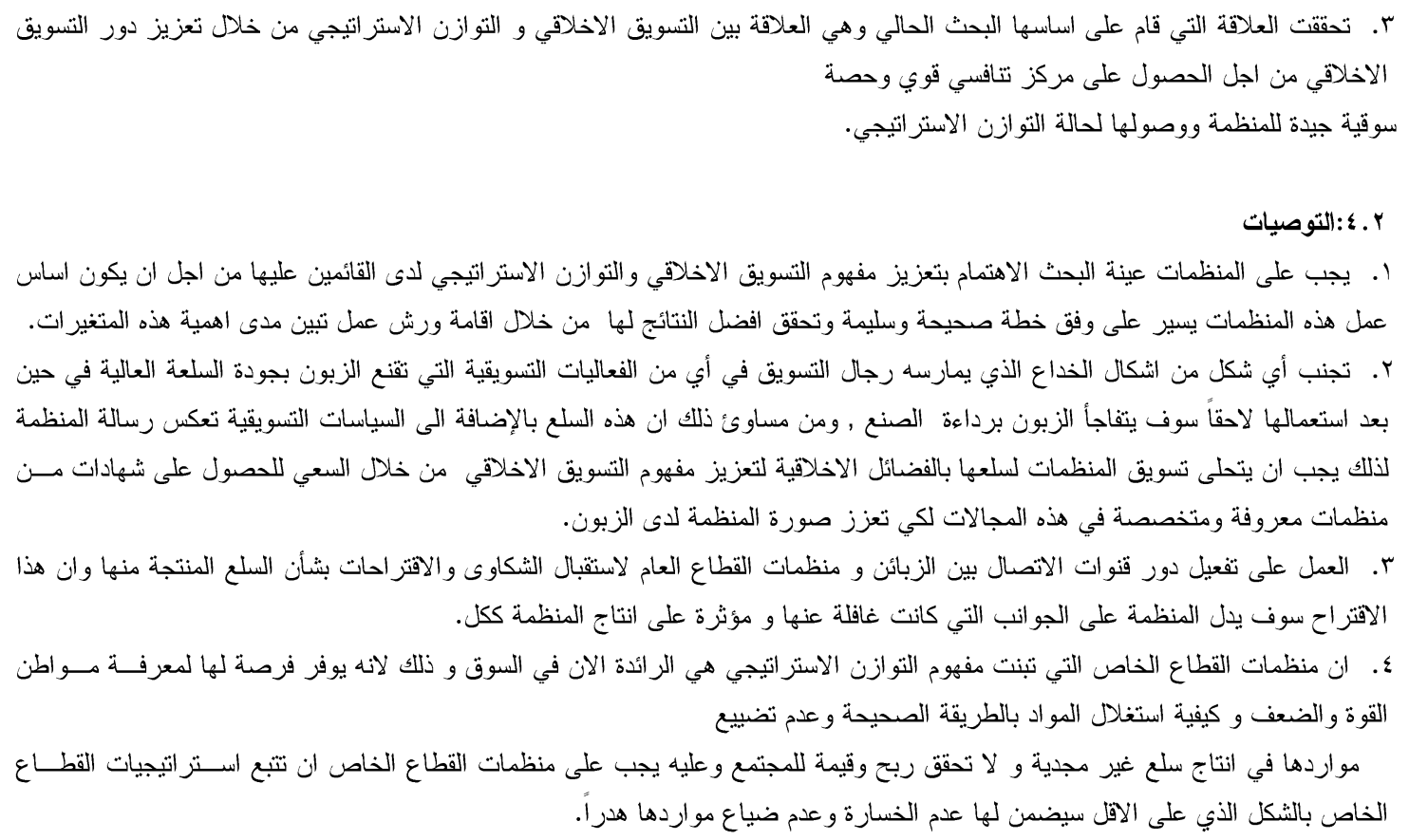

[1] Nguyen, B. and Rowley,C., Ethical and Social Marketing in Asia Incorporating Fairness Management ,Elsevier, 2015.

[2] Akaak, I. P. , "The Influence of Organizational Rank and Role on Marketing Professionals' Ethical Judgments", Journal of Business Ethics Netherlands,vol.15,pp. 605-613,1996.

[3] Vitell,s., Bakir, A., Paolillo,J., Hidalgo,E. R., Al-Khatib J. and Rawwas,M., "Ethical judgments and intentions : a multinational study of marketing professionals", Business Ethics : A European Review Blackwell Publishing, vol 12 nu 2,pp.151-171, 2003.

[4] Arnold, C. , Ethical marketing and the new consumer, John Wiley \& Sons, Ltd , United Kingdom, 2009.

[5] Brei,V. and Bohm,S.,"Corporate social responsibility as cultural meaning management: a critique of the marketing of 'ethical' bottled water", Business Ethics: A European Review Blackwell Publishing Ltd. , USA, Vol 20, No 3 ,pp.233-252, 2011.

[6] Kumar,P. and Mokhtar,S. ,"Marketing Practices Viewed Through Consumer Spectacles" , Market-Tržište Vol. 28, No. 1, pp.29-45, 2016.

[7] Przhedetsky,Y.V.,Przhedetskaya,N.V.,Przhedetskaya,V.Y.,Bondarenko,V.A. and Borzenko,K.V, "The Role of Social-Ethical Marketing and Information and Communication Technologies in Response to Challenges of Oncology", European Research Studies Journal Volume XXI, Special Issue1,pp. 377-386, 2018.

[8] Smith,D. E., Skalnik, J. and Skalnik,P. C. ,"Ethical Behavior of Marketing Managers and MBA Students: A Comparative Study", Teaching Business Ethics vol.3, pp.323-337,1999.

[9] Laczniak, G. R. and Murphy,P. E. , "Normative Perspectives for Ethical and Socially Responsible Marketing" , Marquette University, Journal of Macromarketing, Vol. 26, No. 2,pp.154-177, 2006.

[10] O'Higgins,E. and Kelleher, B. , "Comparative Perspectives on the Ethical Orientations of Human Resources, Marketing and Finance Functional Managers", Journal of Business Ethics vol.56,pp.275-288, 2005.

[11] Baker,M.,Marketing Responsibly Addressing the ethical challenges, The Institute of Business Ethics, London,2009.

[12] Vassilikopoulou,A., Siomkos, G.and Rouvaki, C. , "The Ethical and Unethical Dimensions of Marketing" , Management Review: An International Journal Vol. 3 No. 2 ,pp.49-60,2008 .

[13] Baker,B. L. and Lesch,W. C., "Equity and Ethical Environmental Influences on Regulated Business-to Consumer Exchange" , Journal of Macromarketing, vol.33 ,no.4, pp.322-341, 2013.

[14] Williamson,I.O. ,Cable,D.M. and Aldrich,H.E. ,"Smaller but not necessarily weaker: How small businesses can overcome barriers to recruitment", Managing People in Entrepreneurial Organizations, Elsevier Science Ltd, Vol. 5, pp. 83-106,2002. 
[15] Bordum,A. ," The strategic balance in a change management", Society and Business Review, Emerald Group Publishing Limited, Vol. 5 No. 3, pp. 245-258, 2010.

[16] Mazzei,M.J. ,Ketchen,Jr. and Shook,L. , Understanding strategic entrepreneurship: a " theoretical toolbox ” approach, Int Entrep Manag J, Springer Science+Business Media New York,2016 .

[17] Mcnamara,G., Deephouse,D.L. and Luce,R.A. , "Competitive Positioning Withing and Across a Strategic Group Structure: The Performance of Core, Secondary, and Solitary Firms" , Strategic Management Journal ,Strat. Mgmt, vol.24 ,no. 2, pp.161 - 181,2003.

[18] Leitch,S. and Motion,J. , "Retooling the Corporate Brand: A Foucauldian perspective on normalisation and differentiation" ,The Journal of Brand Management,vol.15, no.1, pp.71-80, 2007.

[19] Boselie,P. ,Brewster,C. and Paauwe,J. , "In search of balance -managing the dualities of HRM: an overview of the issues", Emerald Group Publishing Limited, Vol. 38, No. 5, pp. 461-471,2009.

[20] Lyver,M.J. and Lu,T. ,"Sustaining Innovation Performance in SMEs: Exploring the Roles of Strategic Entrepreneurship and IT Capabilities", Sustainability, vol.2 ,no.10, ,pp.442, 2018.

[21] Deephouse,D.L. , "To be Different, or to be the Same? It's a Question (and Theory) of Strategic Balance", Strategic Management Journal ,Strat. Mgmt. J.,vol.20, pp. 147-166 , 1999.

[22] Ramosaj,B. and Berisha,G. , "Systems Theory and Systems Approach to Leadership" , Iliria International Review-Felix-Verlag, Holzkirchen, Germany and Iliria College, Pristina, Kosovo,vol 1 ,pp.59-79 2014.

[23] Wheelen,T.L. and Hunger, J.D. , Strategic Management and Business Policy TOWARD GLOBAL SUSTAINABILITY, $13^{\text {th }}$ ed, Pearson Education, Inc, 2012.

[24] Schiehll,E. and Landry,S. , "Perceived controllability and fairness in Performance evaluation", Rev. bus. manag., São Paulo, Vol. 16, No. 52, 2014.

[25] Dess,G. , Lumpkin, G. T. , Eisner,A.B. and McNamara,C. , Strategic Management: Text and Cases, $17^{\text {th }} \mathrm{ed,}$ McGraw-Hill Education,2014. 